\title{
Identification of the epitope for anti-cystatin C antibody
}

\author{
Anna Śladewska ${ }^{a}$, Aneta Szymańska ${ }^{a}$, Marlena Kordalskaa, \\ Agnieszka Lewandowskab, Aleksandra S. Kołodziejczyka , \\ Gabriela Paraschivc, Michael Przybylskic and Paulina Czaplewska ${ }^{a *}$
}

\begin{abstract}
Human cystatin C (hCC), like many other amyloidogenic proteins, has been shown to form dimers by exchange of subdomains of the monomeric protein. Considering the model of hCC fibrillogenesis by propagated domain swapping, it seems possible that inhibition of this process should also suppress the entire process of dimerization and fibrillogenesis which leads to specific amyloidosis (hereditary cystatin C amyloid angiopathy (HCCAA)). It was reported that exogenous agents like monoclonal antibody against cystatin $C$ are able to suppress formation of cystatin C dimers. In the effort to find a way of controlling the cystatin fibrillization process, the interactions between monoclonal antibody Cyst-13 and cystatin C were studied in detail. The present work describes the determination of the epitope of hCC to a monoclonal antibody raised against cystatin C, Cyst-13, by MALDI mass spectrometry, using proteolytic excision of the immune complex. The shortest epitope sequence was determined as hCC(107-114). Affinity studies of synthetic peptides revealed that the octapeptide with epitope sequence does not have binding ability to Cyst-13, whereas its longer counterpart, hCC(105-114), binds the studied antibody. The secondary structure of the peptides with epitope sequence was studied using circular dichroism and NMR spectroscopy.
\end{abstract}

Keywords: cystatin C; monoclonal antibody; epitope; mass spectrometry

\section{INTRODUCTION}

Antibody (Ab) play nowadays an important role in research, routine analysis, and diagnostics and it seems that very soon they can be commonly used in immunotherapy. The most promising use of the antibody as a successful therapeutic agents is connected with their ability to suppress the development of some neurodegenerative diseases like Alzheimer's (Bard et al., 2000; Tabira 2010), Huntington (Colby et al., 2004), and prionbased disorders (Donofrio et al., 2005; Wuertzer et al. 2008; Antonyuk et al. 2009). The exact mechanism of the antibody action is not clear. Therefore, comprehensive and detailed studies of the mechanism of the intermolecular interactions, involving mapping of the epitopes and paratopes are necessary.

Human cystatin C ( $\mathrm{hCC}$ ) is an amyloidogenic protein involved in the development of neurodegenerative disorders for which the immunotherapy can be a potential cure. Anti-cystatin C antibody can be the hope for patients suffering from specific angiopathy (HCCAA - hereditary cystatin C amyloid angiopathy) caused by the extremely amyloidogenic L68Q variant of hCC (Abrahamson and Grubb, 1994; Grubb, 2000; Olafsson and Grubb, 2000; Calero et al., 2001). It was proposed that the fibrillization process of cystatin $C$ and its mutants proceeds via propagated domain swapping (Janowski et al., 2001; Jaskolski, 2001; Janowski et al., 2005). In addition, different domain-swapped oligomers may play a role in the fibrillogenesis. Grubb and coworkers described the influence of antibody on the dimerization process of hCC. In their work, the authors used monoclonal antibody raised against hCC, $\operatorname{lgG} 2 \mathrm{~b}(\kappa)$ (Nilsson et al., 2004). It was found that incubation of $h C C$ with guanidinium chloride at $37^{\circ} \mathrm{C}$ gives the dimer of the protein in 2-3 days, and the amyloidogenic L68Q hCC mutant even in
$30 \mathrm{~min}$. The addition of just a catalytic amount of the monoclonal antibody visibly diminished the amount of the dimerized protein. The use of the antibody in the ratio 1:10 and 1:5 (antibody: hCC) almost completely stopped the dimerization process. The results clearly showed that the antibody can be considered as a potential therapeutic agent in amyloidosis caused by aggregation of hCC and its $L 68 \mathrm{Q}$ mutant. As a starting point to immunotherapy in HCCAA, all antigenic determinants on hCC surface should be identified. Then, blocking the epitopes one after the other, it would be possible to find which one is responsible for controlling the dimerization or fibrillization of cystatin C.

\footnotetext{
Correspondence to: P. Czaplewska, Department of Medicinal Chemistry, University of Gdansk, Sobieskiego 18, 80-952 Gdansk, Poland. E-mail: pczaplewska@gmail.com

a A. Śladewska, A. Szymańska, M. Kordalska, A. S. Kołodziejczyk, P. Czaplewska Department of Medicinal Chemistry, University of Gdansk, Sobieskiego 18,80952 Gdansk, Poland

b A. Lewandowska

Laboratory of Biopolymer Structure, Inter-Collegiate Faculty of Biotechnology, University of Gdansk, Medical University of Gdansk, Kładki 24, 80-822 Gdańsk, Poland

c G. Paraschiv, M. Przybylski

Laboratory of Analytical Chemistry and Biopolymer Structure Analysis, University of Konstanz, Universitätsstraße 10, 78464 Konstanz, Germany
}

Abbreviations: ESI, electrospray ionization; $h C C$, human cystatin $C ; H C C A A$, hereditary cystatin $C$ amyloid angiopathy; MALOI, matrix-assisted laser desorption/ionization; MD, molecular dynamics; NHS, N-hydroxysuccinimide; PBS, phosphate buffered saline; TFE, trifluoroethanol; TOF, time of flight; wt, wild type. 
The knowledge of the hCC epitope sequence and structure could be used for (i) the design of the improved, more specific immunization agents to minimize side effects induced by antibody against the whole protein, (ii) the design of antibody that recognize only the specific $\mathrm{hCC}$ epitope, and (iii) monitoring titers of antibody to one particular epitope. For hCC, an increasing number of new sets of high-affinity monoclonal antibody specific to different hCC epitopes is available. They are produced after immunization in mammals with the whole hCC (Olafsson et al., 1988). Probably all these antibody can be present in human fluids, but no studies about anti-cystatin autoantibody are available. Now eight types of monoclonal $\mathrm{Ab}$ anti-hCC are commercially available (Cyst 10, 13, 16, 18, 19, 23, 24, 28). Potentially, they recognize different epitopes on the cystatin C surface, but lack of information about their location and sequence can be the reason for some misleading data or misuse of antibody chosen for an experiment, leading to false positive or false negative results of the analysis.

The combination of isolation of antibody-bound peptides using immuno-affinity techniques followed by the precise identification of epitope peptides by mass spectrometry can be a powerful tool for epitope determination (Stefanescu et al. 2007). The proteolytic foot printing method of epitope mapping was first proposed by Jemmerson and Patterson based on the resistance of the antigenic region to proteolytic cleavage when it is bound to the antibody (Jemmerson and Paterson, 1986). The identification of epitope peptides coming from a mixture of proteolytic digest fragments of the antigen was called epitope extraction. The alternative technique, epitope excision, uses the general resistance of antibody towards enzymatic cleavage by binding the complete antigen to it and afterwards, digesting the antigen by a specific protease to cleave the unbound antigen fragments, leaving the epitope-antibody complex intact. Epitope excision and extraction mass spectrometric identification was used for the direct determination of continuous epitope for antiA $\beta$ antibody (Tian et al., 2002; Tian et al., 2005; Tian et al., 2007) as well as discontinuous epitopes such as the HIV-gp 120 epitope (Hochleither et al., 2000), was successfully used by a number of laboratories (Jeyarajah et al., 1998). An important feature of this approach is that because of non-denaturating conditions, the antigen remains in its native conformation and conformational epitopes can also be determined. The method also offers the possibility of determining not only discontinuous epitopes, but also epitopes which contain an enzymatic cleavage site.

In this work, we present the results of identification and precise location of the epitope for monoclonal antibody Cyst- 13 with the use of epitope extraction/excision mass spectrometry methodology. Circular dichroism and NMR studies were used to evaluate the secondary structure of the identified epitope. Preliminary results of the dimerization process of $\mathrm{hCC}$ in the presence of different amounts of $\mathrm{mAb}$ Cyst- 13 revealed that the antibody can influence the dimerization process.

\section{MATERIALS AND METHODS}

\section{Expression and purification of cystatin $\mathrm{C}$}

Plasmid pHD313 carrying the hCC gene as a fusion protein with OmpA signal peptide for periplasmic expression was obtained as a kind gift from Prof. Anders Grubb (University Hospital, Lund, Sweden). The protein was overexpressed in E. coli strain C41 (DE3) as described previously (Szymanska et al., 2009). The harvested bacteria were resuspended in $10 \mathrm{mM}$ Tris, $\mathrm{pH} 7.4$, containing $10 \%$ glycerol ( $10 \mathrm{ml} / 0.5$ I culture) and then twice flash-frozen and thawed, which led to release of significant amounts of hCC from the periplasmic space. The sample was then centrifuged and the clear supernatant applied onto an S-Sepharose column equilibrated in $10 \mathrm{mM}$ Tris-buffer containing $5 \%$ glycerol, $\mathrm{pH} 7.4$ (buffer A). The adsorbed proteins were eluted with an increasing salt gradient comprising $10 \mathrm{mM}$ Tris, $1 \mathrm{M} \mathrm{NaCl}, 5 \%$ glycerol, $\mathrm{pH} 7.4$ (buffer B). The hCC fractions were collected, dialyzed against $10 \mathrm{mM}$ ammonium bicarbonate $(\mathrm{pH}$ 8), and lyophilized. The protein was purified to homogeneity by mean of gel filtration using Superdex 75 PC 10/300 column run in $20 \mathrm{mM}$ ammonium bicarbonate buffer $(\mathrm{pH}$ 8). The appropriate fraction were collected, lyophilized and stored as solid before further use. The protein purity was characterized by SDS-PAGE electrophoresis, analytical gel filtration on Superdex 75 PC 3.2/30 column, and mass spectrometry.

\section{Peptide synthesis and purification}

The peptides were synthesized according to published methods using standard solid-phase synthesizer (Millipore 9050 Plus PepSynthesizer) and the $\mathrm{Fmoc} / \mathrm{Bu}$ strategy (Atherton and Sheppard, 1989; Fields and Noble, 1990). The protected amino acids and other chemicals were purchased from Peptides International, Fluka, and Sigma-Aldrich. All syntheses were performed on a TentaGel R RAM resin (Rapp Polymers; 1 g, capacity of $0.18 \mathrm{mmol} / \mathrm{g}$ ) with the use of the DIPCI/HOBt methodology; deprotection of the $\alpha$-amino group was carried out with $20 \%$ piperidine in $D M F / N M P=1: 1$. After automatic synthesis and the deprotection of the last $\mathrm{N}$-terminal Fmoc group, the resin was washed with methanol and dried in vacuo. Then, the peptidyl resin was treated with $10 \mathrm{ml}$ of the mixture: trifluoroacetic acid/ $\mathrm{H}_{2} \mathrm{O} /$ phenol/triisopropylsilane (reagent B: 8.8/ $0.5 / 0.5 / 0.2, \mathrm{v} / \mathrm{v}) / 1 \mathrm{~g}$ of resin at room temperature for $2 \mathrm{~h}$. After filtration of the exhausted solid matrix, the solvent was concentrated in vacuo and the residue was triturated with diethyl ether. The crude peptide was purified by reversed-phase high-performance liquid chromatography (RP-HPLC) using a semi-preparative C8 column $(10 \times 250 \mathrm{~mm}, 5 \mu \mathrm{m})$ and Varian Star chromatography system. The aqueous system consisted of $0.1 \%$ ( $v / v)$ TFA in water solution, while the organic phase was $80 \%$ acetonitrile in water, containing $0.08 \%(\mathrm{v} / \mathrm{v})$ TFA.

The elution was carried out by using at first isocratic $10 \%$ organic phase solution and next a linear gradient from 10 to $50 \%$ of the organic phase in $120 \mathrm{~min}$; the flow rate was adjusted to $15 \mathrm{ml} / \mathrm{min}$ and the separation was monitored by UV absorbance at $220 \mathrm{~nm}$.

The peptide-containing fractions were analyzed using the analytical C8 column $(4.4 \times 250 \mathrm{~mm}, 5 \mu \mathrm{m})$ operated by Varian chromatography system, using linear gradient 10 to $40 \%$ organic phase in $20 \mathrm{~min}$. The purity of the lyophilized peptide was analyzed using a linear gradient $0-100 \%$ of organic phase in $60 \mathrm{~min}$ (UV detection at $220 \mathrm{~nm}$ ) and by ESI spectroscopy using ESI-IT-TOF MS mass spectrometer (Shimadzu).

\section{Synthesis of hCC (101-117) via O- to $\mathrm{N}$-acyl transfer}

The hCC (101-117) fragment was synthesized according to published methods using standard solid-phase synthesis techniques with a manual methodology (Atherton and Sheppard, 1989; Fields and Noble, 1990). The TentaGel R RAM resin (Rapp 
Polymers; capacity $0.18 \mathrm{mmol} / \mathrm{g}, 1 \mathrm{~g}$ ) was used as a solid matrix to which amino acids were linked with the use of DIPCI/HOBt methodology. The coupling reaction time at each step was $1 \mathrm{~h}$. Piperidine (20\%) in dimethylformamide was used to remove Fmoc groups at all steps. Boc-Ser-OH and Boc-Tyr-OH were coupled as described above. The subsequent side chain $O$ acylation of these amino acids was started by the activation of the following in sequence amino acid with $N, N^{\prime}$-diisopropylcarbodiimide and $\mathrm{N}$-methylimidazole (NMI) in DCM for 1 min. Next, the solution of the activated amino acid was added to the resin, gently mixed for $30 \mathrm{~s}$, and left for additional $2 \mathrm{~h}$ (Coin et al., 2007). After washing, the next coupling step was performed according to the standard DIPCl/HOBt protocol as described above.

After final Fmoc deprotection and washing with methanol, the protected peptididyl resin was dried in vacuo. Then the resin was treated with reagent $B$ and the crude peptide was isolated and purified as was described above. The purity of the product was assessed by a Maldi-Tof analysis using a Bruker Biflex III Maldi-Tof Mass Spectrometer (Bruker Daltonics).

\section{Sepharose immobilization of the monoclonal antibody}

A sample containing approximately $100 \mu \mathrm{g}$ of monoclonal anticystatin C antibody (Cyst-13, Abcam) was dissolved in $0.2 \mathrm{ml}$ of coupling buffer containing $0.2 \mathrm{M} \mathrm{NaHCO}_{3}$ and $0.5 \mathrm{M} \mathrm{NaCl}(\mathrm{pH} 8.3)$, and the solution was added to $0.06 \mathrm{mg}$ of dry NHS-activated Sepharose (4B, Sigma-Aldrich). The coupling reaction was carried out for $1 \mathrm{~h}$ at $25^{\circ} \mathrm{C}$ under vigorous shaking, then the reaction mixture was loaded onto a $1 \mathrm{ml}$ microcolumn (MoBiTec, Goettingen, Germany) and washed sequentially with blocking solution ( $0.1 \mathrm{M}$ aminoethanol, $0.5 \mathrm{M} \mathrm{NaCl}, \mathrm{pH} 8.3$ ) and washing solution ( $\left.0.2 \mathrm{M} \mathrm{CH}_{3} \mathrm{COONa}, 0.5 \mathrm{M} \mathrm{NaCl}, \mathrm{pH} 4.0\right)$. The column was further incubated for $1 \mathrm{~h}$ at $25^{\circ} \mathrm{C}$ with blocking solution followed by second washing steps as described above. In the final step, the column was washed with $10 \mathrm{ml}$ of the buffer containg $5 \mathrm{mM}$ $\mathrm{Na}_{2} \mathrm{HPO}_{4}$ and $150 \mathrm{mM} \mathrm{NaCl}, \mathrm{pH} 7.5$ and then stored at $4{ }^{\circ} \mathrm{C}$ (Juszczyk et al., 2009).

\section{Binding of hCC or synthetic peptides on anti-hCC mAb- Sepharose (binding test)}

Buffered solution of purified hCC ( $35 \mu \mathrm{g} /$ column) or a synthetic peptide $(10 \mu \mathrm{g} / \mathrm{column})$ was added onto anti-hCC mAb-Sepharose column equilibrated in PBS (pH 7.4) and incubated for $2 \mathrm{~h}$ at $25^{\circ} \mathrm{C}$ with gentle shaking (thermoshaker). The unbound material was removed by washing of the column with $50 \mathrm{ml}$ PBS. The remaining affinity-bound hCC-antibody complex was dissociated using $2 \times 500 \mu$ l of $0.1 \%$ aqueous TFA (pH 2.5) and released hCC was analyzed by MALDI-MS (Juszczyk et al., 2009).

\section{Epitope- excision and extraction mass spectrometry}

For proteolytic epitope excision mass spectrometry, the hCC mAb-Sepharose complex was prepared and the excess of unbound hCC was removed by washing as described above. The hCC-mAb complex was then digested with different enzymes: trypsin (for $2 \mathrm{~h}$ at $27^{\circ} \mathrm{C}$ ), chymotrypsin $\left(2 \mathrm{~h}, 25^{\circ} \mathrm{C}\right.$ ), or with pronase $\left(1 \mathrm{~h}, 40^{\circ} \mathrm{C}\right)$, Glu-C $\left(3 \mathrm{~h}, 25^{\circ} \mathrm{C}\right)$, Lys-C $\left(2 \mathrm{~h}, 37^{\circ} \mathrm{C}\right)$. Addition of the appropriate inhibitor stopped the proteolysis. The supernatant fractions containing unbound digestion products were removed by washing with $20 \mathrm{ml}$ of PBS. The remaining affinity-bound cystatin $\mathrm{C}$ fragments were dissociated by addition of $2 \times 500 \mu \mathrm{l}$ of $0.1 \% \mathrm{TFA} / \mathrm{H}_{2} \mathrm{O}$. The fractions containing released
hCC fragments were collected in Eppendorf tubes and lyophilized for mass spectrometry analysis.

For epitope extraction-mass spectrometry, proteolytic digestion of unbound hCC was performed with the same proteases at identical conditions as described above, and the proteolytic digests were incubated with the affinity antibody-modified columns for $2 \mathrm{~h}$ at $25^{\circ} \mathrm{C}$. The supernatants containing the unbound peptide fragments were removed by washing and the epitope fractions recovered by elution with $0.1 \%$ TFA/ $\mathrm{H}_{2} \mathrm{O}$ as described above (Juszczyk et al., 2009).

\section{Circular dichroism}

CD spectra of $h C C$ wild type ( $w t)$ and its variants were measured in PBS buffer, $\mathrm{pH} 7.4$ in $1 \mathrm{~mm}$ cell on Jasco J-815 polarimeter at $20^{\circ} \mathrm{C}$ using protein samples with an average concentration of $0.33 \mathrm{mg} / \mathrm{ml}$. Three scans in the wave length range $195-250 \mathrm{~nm}$ were collected and averaged. All spectra were corrected for the buffer signal.

\section{Dimer formation}

The dimerization experiments for all studied compounds were performed in PBS buffer, $\mathrm{pH} 7.4$, containing $0.5 \mathrm{M}$ guanidinium chloride at $37^{\circ} \mathrm{C}$ using $1.0 \mathrm{mg} / \mathrm{ml}$ protein samples, according to the previously described protocol (Nilsson et al., 2004).

\section{Gel electrophoresis}

The progress of dimer formation was monitored by native agarose gel electrophoresis on $1 \mathrm{~mm}, 1 \%$ agarose gels in barbiturate buffer, pH 8.9. Gels were fixed in picric acid and next stained with Coomassie Blue R-250 stain (Szymanska et al., 2009).

\section{${ }^{1}$ H-NMR spectroscopy}

The NMR spectra of the epitope peptide (hCC 107-114) were measured on VARIAN $500 \mathrm{MHz}$ spectrometer. The following 2D ${ }^{1} \mathrm{H}$-NMR spectra were recorded at $305 \mathrm{~K}$ : DQF-COSY (Piantini et al., 1982), TOCSY (Bax and Freeman, 1985) $(80 \mathrm{~ms})$ and ROESY (Bax and Davis, 1985) (250 ms). The sample was dissolved in $\mathrm{H}_{2} \mathrm{O} /{ }^{2} \mathrm{H}_{2} \mathrm{O}$ (9:1 by vol.) ( $\mathrm{pH}$ of the solution of the epitope peptide was 7) with the sample concentration of $5 \mathrm{mM}$. The spectra were processed using VARIAN 4.3 software (Varian Instruments, Palo Alto, CA, USA) and analyzed with the XEASY program (Bartels et al., 1995). The spectra were calibrated against the HDO signal taking into account the temperature drift of the reference signal given by the equation $\delta_{1 \mathrm{H}(T)}=5.060-0.0122 t+\left(2.11 \times 10^{-5}\right) t^{2}$, where $t$ is the temperature in ${ }^{\circ} \mathrm{C}$ (Gottlieb et al., 1997). Proton signals were assigned based on the TOCSY spectra. The sequential analysis of the peptide was confirmed by the ROESY spectra (Bax and Davis, 1985). The coupling constants between $\mathrm{NH}$ and $\mathrm{H}_{Q x}$ protons $\left({ }^{3} \mathrm{~J}_{\mathrm{HNH}}\right)$ were obtained from two-dimensional DQF-COSY and one-dimensional $1 \mathrm{H}$ spectra. The intensities of ROE signals were estimated from the ROESY spectra.

\section{Three-dimensional structure calculations}

The ROE inter-proton cross-peaks of the epitope peptide were derived from $2 \mathrm{D}{ }^{1} \mathrm{H}-\mathrm{NMR}$ ROESY spectra, and vicinal coupling constants ${ }^{3} \mathrm{~J}_{\mathrm{HNH} \text {. }}$ were obtained from $2 \mathrm{D}^{1} \mathrm{H}$-NMR DQF-COSYand 1D ${ }^{1} \mathrm{H}-\mathrm{NMR}$ spectra. In the first step, the ROESY peak volumes were converted to upper distance bounds by using CALIBA 
(Guntert et al., 1991) of the DYANA package (Guntert et al., 1997). In the next step, torsion angles, based on the Bystrov-Karplus equation (Bystrov, 1976), were generated using the HABAS algorithm of the DYANA package (Guntert and Wüthrich, 1991). The upper distance limits and torsional angles were used as restraints in molecular dynamics calculations.

Molecular dynamics simulations with the time-averaged methodology (TAV) (Torda et al., 1989; Pearlman and Kollman, 1991; Case et al., 2004) were carried out with the AMBER force field (Weiner et al., 1987) using the AMBER 8.0 package (Case et al., 2004). The interproton distances and the dihedral angles were restrained with the force constants $k=20 \mathrm{kcal} /\left(\mathrm{mol} \times \AA^{2}\right)$ and $k=2 \mathrm{kcal} /\left(\mathrm{mol} \times \mathrm{deg}^{2}\right)$, respectively. The dihedral angles $\omega$ were restrained with a center at $180^{\circ}$ and $k=10 \mathrm{kcal} /$ $\left(\mathrm{mol} \times \mathrm{deg}^{2}\right)$. The improper dihedral angles centered at the $\mathrm{C}^{\alpha}$ atoms (defining the chirality of amino acid residues) were restrained with $k=50 \mathrm{kcal} /\left(\mathrm{mol} \times \mathrm{deg}^{2}\right)$. MD simulations, using the restraints from the NMR data collected at $305 \mathrm{~K}$, were carried out in a TIP3P periodic water box at constant volume (Mahoney and Jorgensen, 2000), with the particle-mesh Ewald (1921) procedure for long-range electrostatic interactions (Darden et al., 1993). MD simulations with time-averaged restraints were run at four temperatures: $305,400,500,600 \mathrm{~K}$. The purpose of running simulations at many temperatures including elevated temperatures was to enhance sampling (Skwierawska et al., 2008). All TAV MD runs were carried out with a time step of $2 \mathrm{fs}$ (Ryckaert et al., 1977), and the total duration of the run was $2 \mathrm{~ns}$. Coordinates were saved every 2000 steps of MD simulations. From every trajectory, 200 final conformations were collected for the analysis of the epitope peptide structure. The structures from four trajectories were combined together (800 structures from all runs were collected). All conformations were clustered with the use of the MOLMOL program (Koradi et al., 1996). An RMS deviation cut-off of $5.0 \AA$ was used in the clustering procedure. The clustering procedure provided five families of conformations for the epitope peptide. The RMS deviation was calculated based on residues from 2 to 7 . Terminal residues were excluded from comparison because of their high mobility, which caused a rapid increase in the number of conformational families during clustering.

\section{RESULTS}

\section{Identification of the hCC epitope recognized by monoclonal antibody Cyst-13}

Proteolytic excision- and extraction-mass spectrometry method was used for the hCC-epitope identification. The general procedure is presented in Figure 1. Its principle is that one of the complex components (mAb Cyst-13) is attached to a solid matrix that simplifies the workout of the immune complex and allows efficient removal of the unbound protein (hCC) or its fragments. Mass spectrometry analysis applied for the epitope identification gives the possibility of using minimal amount of proteins and enzymes, making the whole procedure simple and cheap. In the analysis, all kinds of proteolytic enzymes can be used. The protocol consists of two complementary variants: epitope-excision and epitope-extraction. The first procedure starts with complex formation followed by proteolytic digestion, while epitope extraction procedure starts with digestion of the protein (hCC) in a solution. Further procedure is identical as for

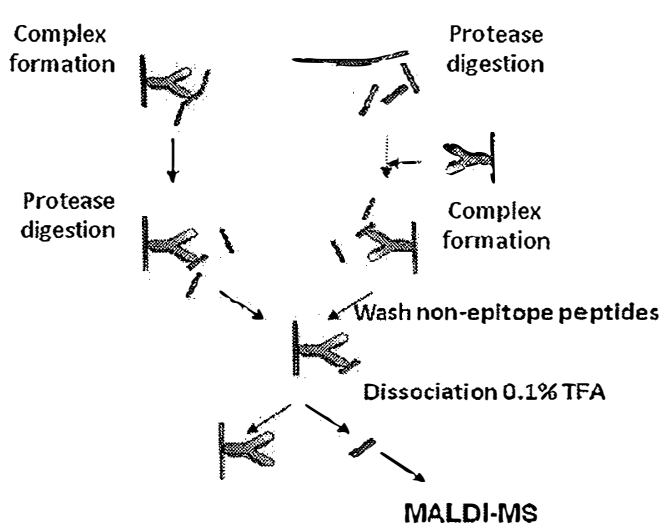

Figure 1. Schematic presentation of the methodology of mass spectrometric epitope mapping procedure: epitope excision with immobilized antibody.

the epitope-excision procedure variant-washing, elution of bound fragments and MS analysis.

\section{Immobilization of mAb Cyst-13 on a Sepharose microcolumn}

The monoclonal antibody was immobilized on NHS-activated Sepharose (see Materials and Methods), and the activity of the mAb Cyst-13 affinity column was ascertained by binding of wt hCC in affinity mass spectrometry experiment. Cystatin $C$ was incubated with the anti-hCC mAb immobilized on Sepharose and the created complex, after a washing with PBS (pH 7.4) steps, was dissociated with the use of $0.1 \%$ TFA. The MALDI-TOF spectra were registered for three separately collected fractions: the supernatant (containing an excess of the unbound hCC), the last wash (containing the last $\mathrm{ml}$ from the column after washing with PBS) and the elution fraction (containing the bound protein released after complex dissociation). Before the mass spectrometry analysis all samples were desalted using the Zip-Tip procedure. The analysis of MS spectra confirmed binding of hCC to monoclonal antibody Cyst-13 by showing two ions: molecular $(\mathrm{M}+\mathrm{H})^{+}$and multiply charged ion $(\mathrm{M}+2 \mathrm{H})^{2+}$ in the elution fraction (data not shown).

Next, the set of epitope excision and extraction experiments was carried out with each of the enzymes: trypsin, chymotrypsin, and pronase.

Trypsin digestion: In the epitope excision experiment, $\mathrm{hCC}$ was applied onto the previously prepared and affinity checked mAb column. Then the hCC-mAb complex was digested with trypsin. Extensive washing after the digestion procedure allowed removal of all unbound cystatin fragments. Eventually, the elution step was performed with $0.1 \% \mathrm{TFA} / \mathrm{H}_{2} \mathrm{O}$. Mass spectrometry analysis of all fractions after tryptic digestion of the hCC-mAb complex, presented in Table 1 , revealed the presence of middle and $\mathrm{N}$ terminal fragments of hCC in the supernatant fraction. The last wash fraction was, as expected, clear. In the elution fraction only full sequence hCC and its truncated hCC (93-120) form were present. This suggested that the N-terminal part of hCC is available for the enzyme and is not shielded by the antibody. In the epitope-extraction procedure, when the trypsin digest of cystatin $C$ was put to react with the immobilized antibody, three fragments of hCC: $54-70$ (m/z 1922.2), $55-70$ (m/z 1794.1), and 93-120 ( $\mathrm{m} / \mathrm{z} 3167.6)$ were observed to bind to the immobilized 


\begin{tabular}{|c|c|c|c|c|c|c|}
\hline $\begin{array}{l}\text { Epitope } \\
\text { excision }\end{array}$ & Fraction & hCC fragment & Sequence & $\begin{array}{l}{[\mathrm{M}+\mathrm{H}]^{+\cdot}} \\
\text { theoretical }\end{array}$ & $\begin{array}{l}{[\mathrm{M}+\mathrm{H}]^{+}} \\
\text {observed }\end{array}$ & $\begin{array}{c}{[\mathrm{M}+2 \mathrm{H}]^{2 \cdot}} \\
\text { observed }\end{array}$ \\
\hline \multirow{12}{*}{ Trypsin } & \multirow{9}{*}{ Supernatant } & $54-70$ & KQNAGVNYFLDVELGR & 1922.4 & 1922.2 & - \\
\hline & & $9-24$ & LVGGPMDASVEEEGVR & 1644.8 & 1643.9 & - \\
\hline & & $9-25$ & LVGGPMDASVEEEGVRR & 1802.0 & 1800.8 & - \\
\hline & & $95-114$ & AFCSFQIYAVPWQGTMTLSK & 2278.1 & 2277.8 & - \\
\hline & & $26-45 / 76-94$ & ALDFAVGEYNKASNDMYHSR/ & 2289.6 & 2290.2 & - \\
\hline & & & TQPNLDNCPFHDQPHLKRK & & & \\
\hline & & $94-114$ & KAFCSFQIYAVPWQGTMTLSK & 2407.9 & 2407.6 & - \\
\hline & & $26-51$ & ALDFAVGEYNKASNDMYHSRALQWVR & 2956.3 & 2956.5 & - \\
\hline & & $26-53$ & ALDFAVGEYNKASNDMYHSRALQWRAR & 3183.6 & 3184.0 & - \\
\hline & Wash & - & - & - & - & - \\
\hline & \multirow[t]{2}{*}{ Elution } & $1-120$ & & - & - & 6674.1 \\
\hline & & $9-120$ & & - & - & 6270.6 \\
\hline
\end{tabular}

antibody (Table 2). The first two identified peptides are the fragments of loop 1 , that differ only by $\mathrm{N}$-terminal lysine residue which was not cleaved by trypsin and therefore can be treated as one cleavage product, and the third is in $\beta$ sheet region; the fragment 93-120 is located at $C$-terminal part of hCC, namely in $\beta 4-L 2-\beta 5$ sequence. The results of this experiment were difficult to be interpreted, however it is possible, that the presence of $L 1$ loop fragment arose from non-specific interactions of this peptides with either the immobilized antibody or the resin. If this fragment was a part of a "split" epitope it should also observed in the epitope excision experiment but was not. To further pursue this problem and establish which of the peptides corresponds to the real epitope, digestions with different enzymes were performed.

Chymotrypsin digestions: In contrast to the results of the trypsin treatment of the hCC-Ab complex, the analogous experiment with chymotrypsin gave relatively clear information about the position of the binding site. The epitope-excision and -extraction experiments with chymotrypsin performed in the same manner as described for the first enzyme revealed that in the elution fractions in both experiments, hCC (86-120) fragment of hCC was present (Table 3, Figure 2). This suggests that the potential epitope for monoclonal antibody Cyst-13 is located in C-terminal part of cystatin C.

The digestion experiments with endoproteinase Glu-C (serine protease cleaving peptide bonds C-terminally to glutamic acid) and Lys-C (serine protease that specifically cleaves peptide bonds C-terminally to lysine) did not give any satisfying results. None of hCC fragments was present in the elution fractions. Although the digestion in solution in both cases gave cystatin fragments, none of them was found to bind to the antibody. The digestion of the affinity complex did not reveal any fragment which could be identified as the epitope. In our hands, only trypsin and chymotrypsin were working fine for cystatin C. Therefore, to get direct information about the epitope sequence, we decided to use pronase which is an unspecific protease cleaving a peptide substrate into its individual amino acids. It was found earlier that this enzyme is suitable for an epitope-excision protocol (Juszczyk

\begin{tabular}{|c|c|c|c|c|c|}
\hline $\begin{array}{l}\text { Epitope } \\
\text { excision }\end{array}$ & Fraction & hCC fragment & Sequence & $\begin{array}{l}{[\mathrm{M}+\mathrm{H}]^{+}} \\
\text {theoretical }\end{array}$ & $\begin{array}{l}{[\mathrm{M}+\mathrm{H}]^{+}} \\
\text {observed }\end{array}$ \\
\hline \multirow[t]{13}{*}{ Trypsin } & \multirow[t]{9}{*}{ Supernatant } & $9-25$ & LVGGPMDASVEEEGVRR & 1802.0 & 1801.2 \\
\hline & & $25-36$ & RALDFAVGEYNK & 1383.5 & 1382.7 \\
\hline & & $26-36$ & ALDFAVGEYNK & 1226.6 & 1226.6 \\
\hline & & $93-114$ & RKAFCSFQIYAVPWQGTMTLSK & 2564.0 & 2563.7 \\
\hline & & $26-53$ & ALDFAVGEYNKASNDMYHSRALQVRAR & 3183.6 & 3184.1 \\
\hline & & $26-45 / 76-94$ & ALDFAVGEYNKASNDMYHSR/TQPNLDNCPFHDQPHLKRK & 2289.6 & 2290.1 \\
\hline & & 94-114 & KAFCSFQIYAVPWQGTMTLSK & 2407.9 & 2408.2 \\
\hline & & $71-92$ & TTCTKTQPNLDNCPFHDQPHLK & 2539.9 & 2540.1 \\
\hline & & $71-93$ & TTCTKTQPNLDNCPFHDQPHLKR & 2696.0 & 2696.7 \\
\hline & Wash & - & - & - & - \\
\hline & \multirow[t]{3}{*}{ Elution } & $54-70$ & KQNAGVNYFLDVELGR & 1922.2 & \\
\hline & & $55-70$ & QNAGVNYFLDVELGR & 1794.8 & \\
\hline & & $93-120$ & RKAFCSFQIYAVPWQGTMTLSKSTCQDA & 3170.5 & \\
\hline
\end{tabular}




\begin{tabular}{|c|c|c|c|c|c|}
\hline Chymotrypsin & Fraction & hCC fragment & Sequence & $\begin{array}{l}{[\mathrm{M}+\mathrm{H}]^{+}} \\
\text {theoretical }\end{array}$ & $\begin{array}{l}{[M+H]^{+}} \\
\text {observed }\end{array}$ \\
\hline \multirow[t]{4}{*}{ Extraction } & Supernatant & $63-85$ & FLDVELGRTTCTKTQPNLDNCPF & 2613.8 & 2613.9 \\
\hline & & $64-85$ & LDVELGRTTCTKTQPNLDNCPF & 2466.7 & 2466.9 \\
\hline & Wash & - & - & - & - \\
\hline & Elution & $86-120$ & HDQPHLKRKAFCSFQIYAVPWQGTMTLSKSTCQDA & 4025.6 & 4024.9 \\
\hline \multirow[t]{3}{*}{ Excision } & Supernatant & $63-85$ & FLDVELGRTTCTKTQPNLDNCPF & 2613.9 & 2613.8 \\
\hline & Wash & - & - & - & - \\
\hline & Elution & $86-120$ & HDQPHLKRKAFCSFQIYAVPWQGTMTLSKSTCQDA & 2613.8 & 4026.2 \\
\hline
\end{tabular}

et al., 2009). The experiment was performed for wt hCC-mAb complex. The analysis of MS spectra of the elution fraction allowed us to identify one hCC fragment responsible for binding to the antibody: hCC (101-117), IYAVPWQGTMTLSKSTC (Table 4). As it is generally known that a typical epitope consists of about 811 amino acid residues (Rock, 1996), we decided to look for a shorter epitope sequence.

Pronase digestions of hCC fragments: To confirm the binding properties of the C-terminal fragment of hCC, binding experiments with different synthetic hCC fragments were performed (Table 5). The binding ability of hCC (93-120) and the shorter (101-117) fragment was confirmed by their presence on MS spectra of the elution fraction. The results of this experiment allowed us to use hCC fragments in epitope excision experiments with pronase. This enzyme enable us to define the epitope sequence as much precisely as possible, as it is able to cleave the protein into individual amino acids during the digestion process. The epitope excision procedures for hCC (93-120) and hCC (101117)-mAb complexes were performed. The MS analysis of the fractions after complex dissociation in both experiments revealed six hCC fragments. The analysis of the results revealed that the common sequence for all of them is located between residue 107 and $114,{ }^{107}$ QGTMTLSK ${ }^{114}$ (for the representative spectrum - see Figure 3). Nevertheless, when the synthetic hCC (107-114) was used in the affinity experiment with mAb Cyst-13, no binding of the peptide to the antibody was observed. To find the shortest, efficiently binding sequence, the epitope peptide was prolongated from the $\mathrm{N}$-terminus. Two additional residues from the

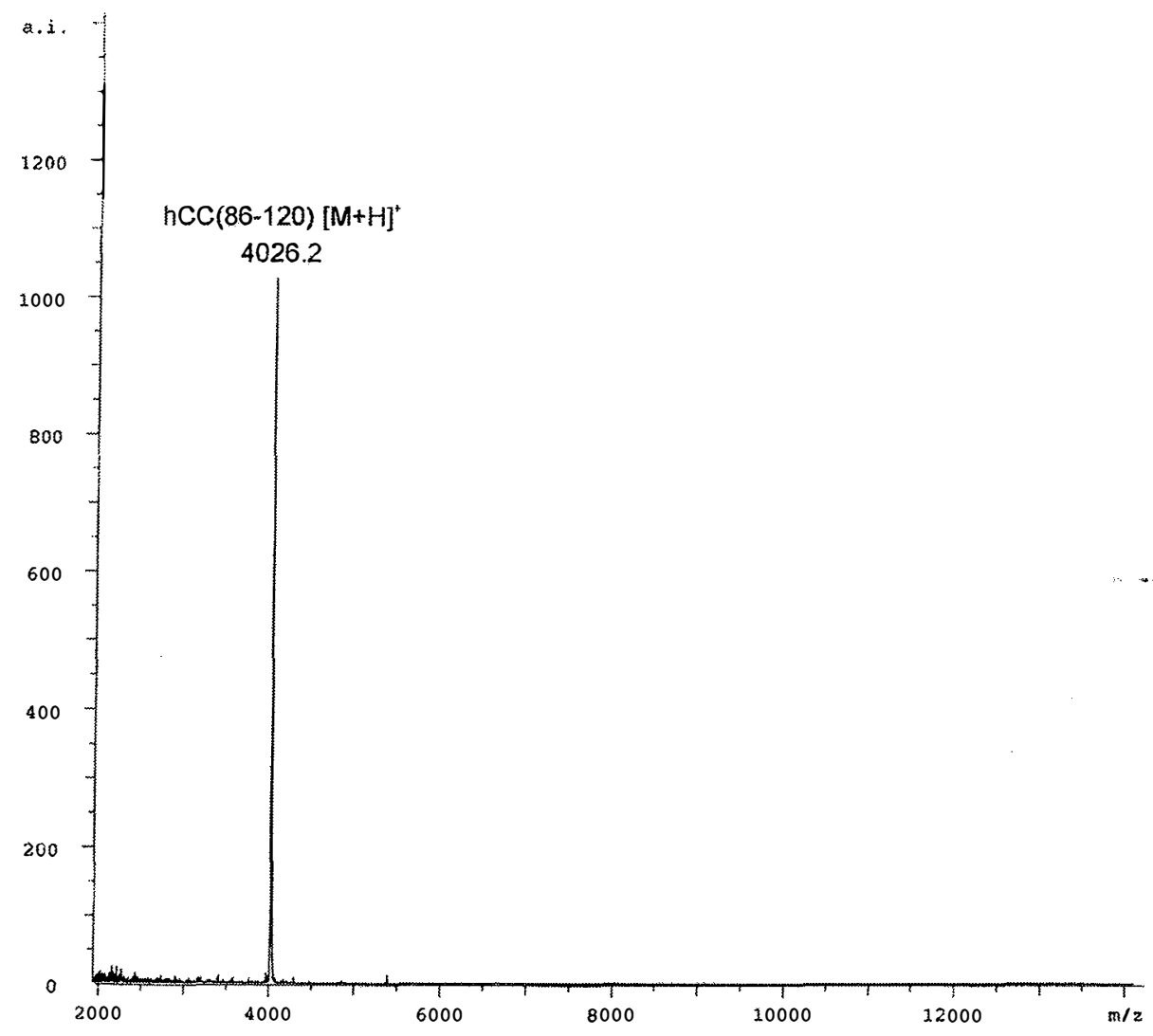

Figure 2. MS spectrum of elution fraction after epitope excision experiment with chymotrypsin. 
Table 4. Peptide fragments dentified in the elution traction after epitope excision of hec with pronase

Epitope excision with pronase and full length cystatin C-elution fraction

$\begin{array}{llcc}\text { hCC fragment } & \text { Sequence } & {[\mathrm{M}+\mathrm{H}]^{+}{ }_{\text {theoretical }}} & {[\mathrm{M}+\mathrm{H}]^{+{ }^{+}} \text {observed }} \\ 101-117 & \text { IYAVPWQGTMTLSKSTC } & 1885.0 & 1884.9\end{array}$

\begin{tabular}{|c|c|c|c|c|}
\hline Fraction & hCC fragment & Sequence & $\begin{array}{l}{[\mathrm{M}+\mathrm{H}]^{+}} \\
\text {theoretical }\end{array}$ & $\begin{array}{l}{[\mathrm{M}+\mathrm{H}]^{+}} \\
\text {observed }\end{array}$ \\
\hline Supernatant & $93-120$ & Ac-RKAFCSFQIYAVPWQGTMTLSKSTCQDA & 3210.1 & 3210.0 \\
\hline Wash & - & - & - & - \\
\hline Elution & $93-120$ & Ac-RKAFCSFQIYAVPWQGTMTLSKSTCQDA & 3210.1 & 3210.0 \\
\hline Supernatant & $101-117$ & IYAVPWQGTMTLSKSTC & 1885.0 & 1885.0 \\
\hline Wash & - & - & - & - \\
\hline Elution & $101-117$ & IYAVPWQGTMTLSKSTC & 1885.0 & 1885.0 \\
\hline Supernatant & $105-114$ & PWQGTMTLSK & 1147.4 & 1147.7 \\
\hline Wash & - & - & - & - \\
\hline Elution & $105-114$ & PWQGTMTLSK & 1147.4 & 1147.6 \\
\hline Supernatant & $107-114$ & QGTMTLSK & 864.0 & 864.0 \\
\hline Wash & - & - & - & - \\
\hline Elution & - & - & - & - \\
\hline
\end{tabular}

natural hCC sequence were sufficient to secure the efficient interactions with $\mathrm{mAb}$ (Table 5). All the experiments give evidence that 10 amino acid epitope sequence PWQGTMTLSK, hCC (105-114), is responsible for binding monoclonal antibody Cyst-13 to hCC.

\section{Circular dichroism studies}

The circular dichroism studies of the epitope peptide (hCC 107114 ) and its longer versions (the epitope prolonged at the $\mathrm{N}$ terminus by two and four residues from the hCC sequence) revealed subtle differences in their secondary structure which may explain the differences in binding the antibody. In PBS, at pH 7.4 all peptides adopt the same unordered structure, but addition of trifluorethanol (TFE) differentiates their propensity for acquiring more ordered structures. In the case of the epitope octapeptide upon TFE addition only some turns appear, but the peptide with two additional residues (decapeptide) forms a wellresolved helical conformation. In $10 \%$ TFE, all peptides spectra show the minimum at $198 \mathrm{~nm}$, which does not change in $50 \%$ TFE only for the epitope octapeptide. In the CD spectra of two other peptides, the minimum shifted to $202 \mathrm{~nm}$ and in the spectrum of

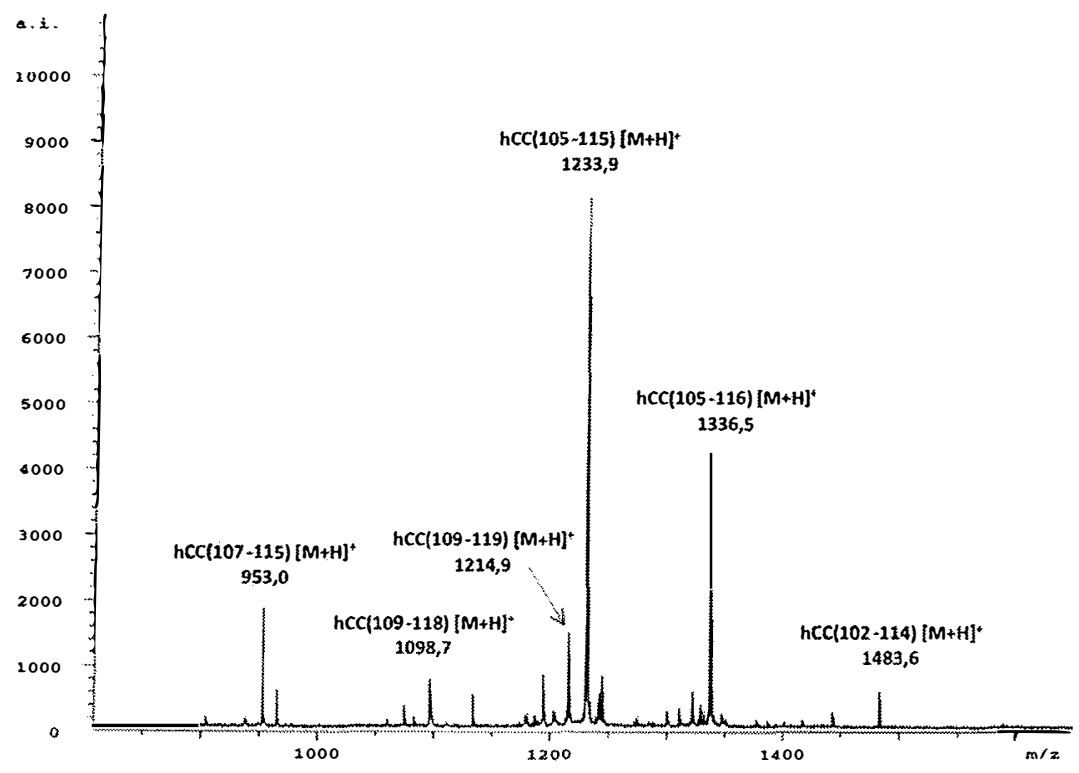

Figure 3. Pronase epitope excision mass spectrum results for hCC (93-120). 
the dodecapeptide, a second minimum around $220 \mathrm{~nm}$ started to form. The peptide hCC (103-114) in trifluoroethanol was found the most helical one (Figure 4).

\section{NMR measurements and structure determination}

Initially, for NMR investigation hCC (105-114), the decapeptide which binds to the antibody, was chosen. Unfortunately, because

A

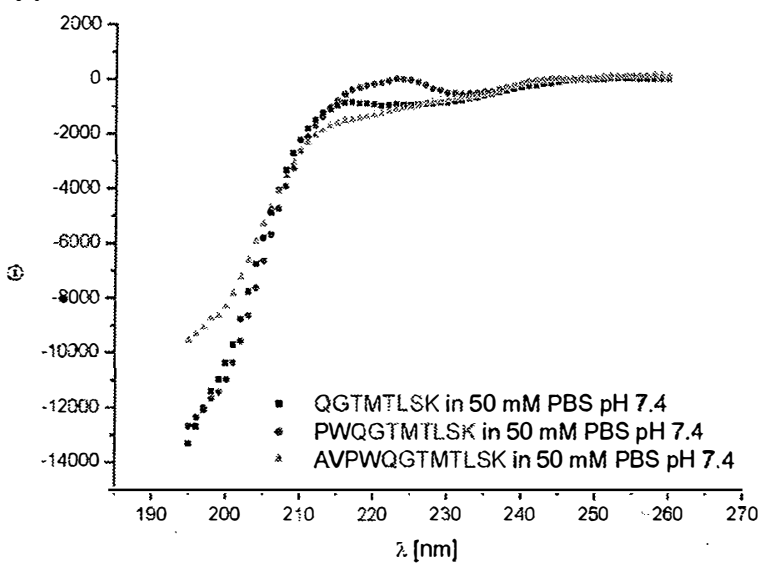

C

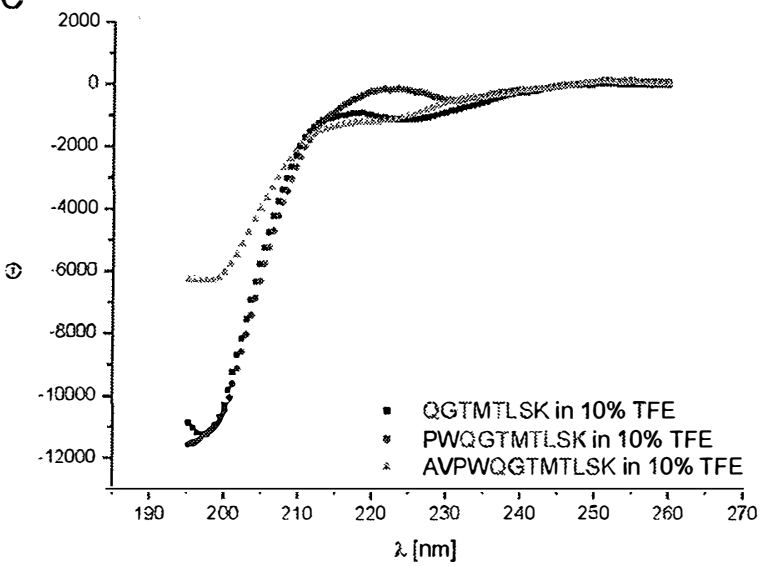

E

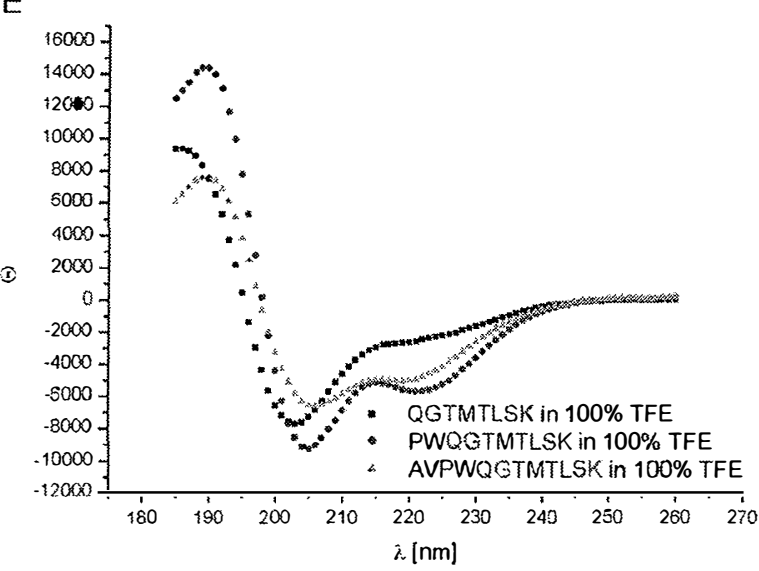

of the fast hydrogen/deuterium exchange observed for this compound, at all applied conditions, we were not able to record, interpretable 2D ${ }^{1} \mathrm{H}$-NMR spectra allowing us to solve the structure. The nature of the high hydrogen/deuterium exchange rate remains unclear and more research is needed to explain this phenomenon. Surprisingly, for the shorter, 8-amino-acid-residue fragment, encompassing the epitope sequence directly determined using the epitope excision method, the observed

B

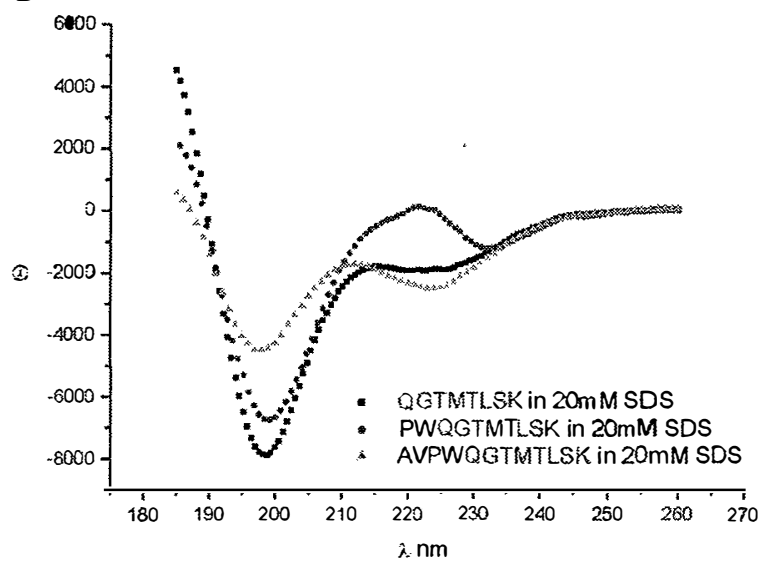

D

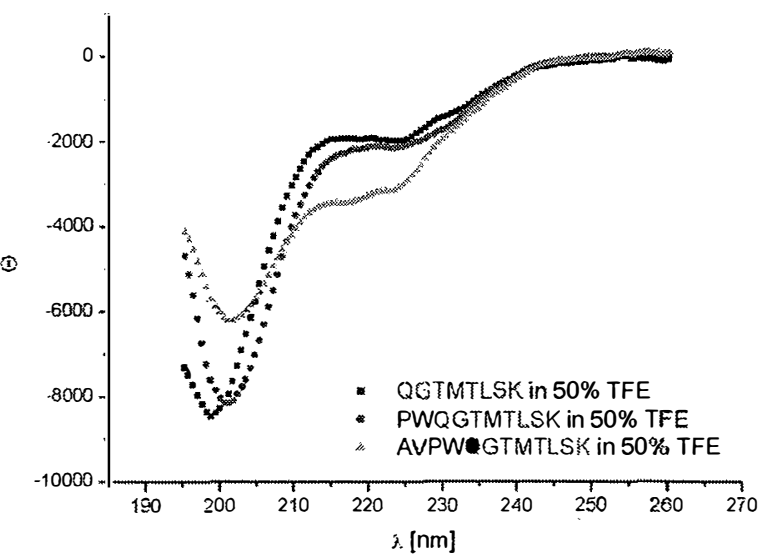

Figure 4. Circular dichroism spectra of hCC fragments registered in (A) phosphate buffer pH 7.4; (B) $20 \% \mathrm{SDS}$; (C) $10 \%$ TFE/ $\mathrm{H}_{2} \mathrm{O}$; (D) $50 \%$ TFE/ $\mathrm{H}_{2} \mathrm{O}$; (E) $100 \% \mathrm{TFE} / \mathrm{H}_{2} \mathrm{O}$. 


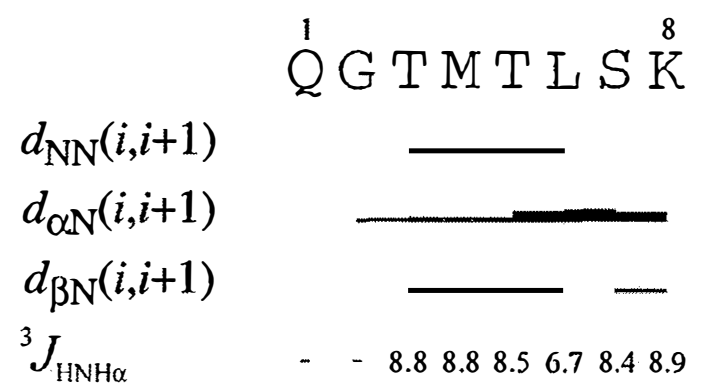

Figure 5. ROE effects corresponding to the interproton distances and the ${ }^{3} \mathrm{~J}_{\mathrm{NHH} \alpha}$ coupling constants of epitope measured in $\mathrm{H}_{2} \mathrm{O}$ at $305 \mathrm{~K}$ at $\mathrm{pH}=7$ The height (vertical thickness) of the bars reflects the strength of the ROE correlation as strong, medium, or weak.

exchange rate was much slower and it allowed us to collect sufficient data for further analyses. The $2 \mathrm{D}^{\prime} \mathrm{H}-\mathrm{NMR}$ spectra of the epitope octapeptide were recorded in water at $\mathrm{pH} 7$ at $305 \mathrm{~K}$. In Figure 5, the ROE effects corresponding to interproton distances and the values of the ${ }^{3} \mathrm{~J}_{\mathrm{NHH} \alpha}$ coupling constants for NMR measurements carried out at $305 \mathrm{~K}$ are presented.

In the recorded spectra sequential, mostly very strong $\mathrm{H}_{\alpha}(\mathrm{i})-$ $H_{N}(i+1)$ ROE connectivities were observed. The $H_{\beta}(i)-H_{N}(i+1)$ connectivities were much weaker, but could also be found. Additionally, for the epitope octapeptide $\mathrm{H}_{N}(i)-\mathrm{H}_{N}(i+1)$ connectivities in the middle of the sequence (Thr3-Leu6) were observed, suggesting that the structure in this region is bent (Wüthrich, 1986). The structural data summarized in Figure 5 were used to carry out MD simulations of the epitope structure with time-averaged restraints, in order to determine the structure of the peptide.

The MD simulations with NMR restraints resulted in five families of conformations shown in Figure 6. Most of these families exhibit a bent structure in the middle of the sequence, manifested by the $H_{N}(i)-H_{N}(i+1)$ connectivities observed in this part of the sequence (Figure 6).

\section{Suppression of hCC dimerization by monoclonal antibody}

Cystatin C, and particularly its $\mathrm{L} 68 \mathrm{Q}$ mutant, shows a significant tendency towards dimerization and oligomerization. Monomeric hCC forms domain-swapped dimers upon crystallization (Janowski et al., 2001, 2005), or in the presence of some destabilizing agents (Ekiel and Abrahamson, 1996), whereas its mutant forms dimers much more easily both in vitro (Abrahamson and Grubb, 1994) and in human body fluids (Olafsson and Grubb, 2000). In this work monoclonal antibody again st hCC were checked as potential inhibitor of the protein aggregation. From a therapeutic point of view, it would be interesting to find particular target for the antibody-the epitope sequence. The first information about the $\mathrm{mAb}$ influence on $\mathrm{hCC}$ dimerization was published by Grubb and co-workers (Nilsson et al., 2004). It was established that monoclonal antibody against hCC $(\operatorname{lgG} 2 \mathrm{~b}(\kappa))$ is able to inhibit dimerization of cystatin C, both wt and L68Q mutant. For our studies, we have chosen different monoclonal antibody than the Swedish group, commercially available antibody, Cyst-13. The incubation system described previously by Grubb was used. The incubation of cystatin $C$ was performed in PBS buffer at $\mathrm{pH} 7.4$ with $0.5 \mathrm{M}$ guanidinium chloride at $37^{\circ} \mathrm{C}$. At these conditions, cystatin $C$ forms dimers by $3 D$ domain swapping mechanism. To check the influence of the studied antibody on the dimerization process, varying amounts of $\mathrm{mAb}$ Cyst- 13 were added to hCC samples (antibody: cystatin C molar ratio $=1: 50 ; 1: 20 ; 1: 6 ; 1: 4)$, and the mixtures were incubated for 9 days. The progress of the dimerization process was estimated from agarose gel electrophoresis of the incubated $\mathrm{hCC} / \mathrm{mAb}$ Cyst-13 mixtures. In a control experiment, the $\lg \mathrm{G} 2 \mathrm{~b}(\kappa)$ antibody against cystatin $C$ were incubated with $\mathrm{hCC}$ and the effects of both antibodies were compared (Figure 7). The incubation of hCC with mAb Cyst-13 showed the suppression of the dimerization
A)

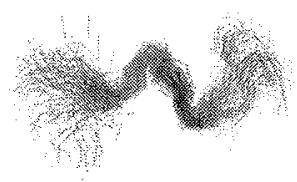

B)

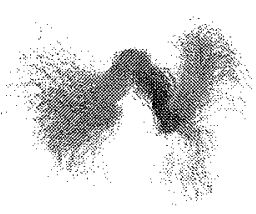

C)

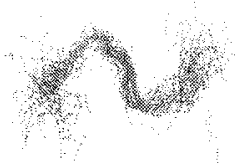

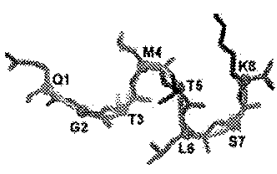
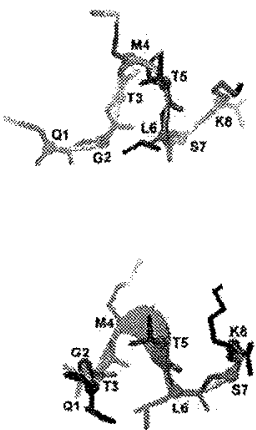

D)
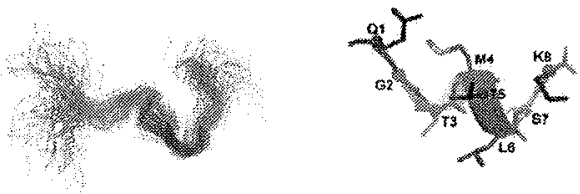

E)

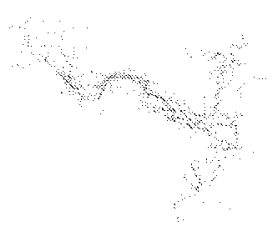

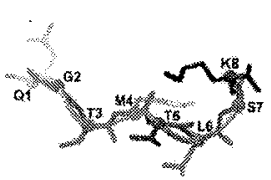

Figure 6. Five families of conformations of epitope obtained by using time-averaged MD methodology with restraints from NMR measurements at $305 \mathrm{~K}$. Left columns show all conformations from a family (only backbones are shown for clarity), right columns show the lowest-energy conformation from the corresponding family (all heavy atoms are shown). 800 conformations were subjected to a cluster analysis, leading to the following numbers and percentages of each clustered family: (a) 422 (52.7\%), (b) 158 (19.8\%), (c) 151 (18.9\%), (d) 50 (6.3\%), (e) 19 (2.4\%). 


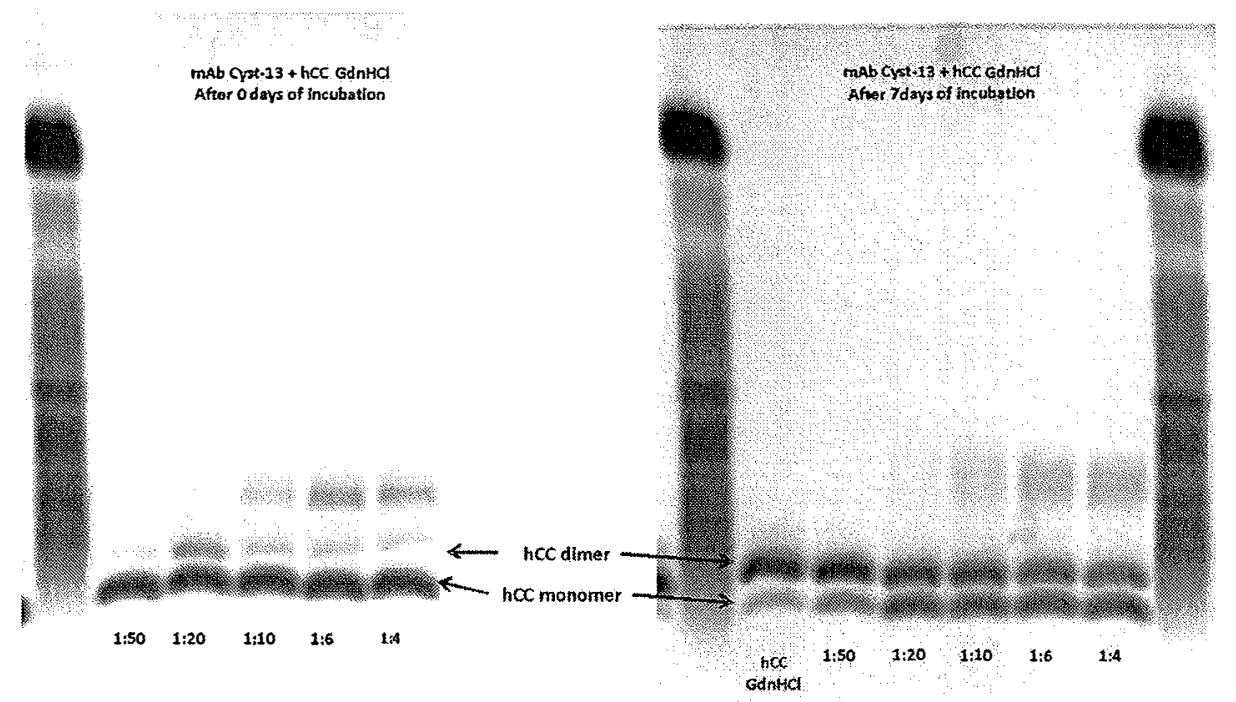

Figure 7. Gel electrophoresis comparison for hCC and mAb Cyst-13 incubated for 7 days.

process for all $\mathrm{mAb} / \mathrm{hCC}$ molar ratios applied. Even the smallest amount of the antibody slightly suppressed the dimer formation in comparison with the dimerization of the native protein. The comparative time dependent studies for both antibodies used (Cyst- 13 and $\lg \mathrm{G} 2 \mathrm{~b}(\kappa) ; \mathrm{mAb} / \mathrm{hCC}$ molar ratio $=1 / 10$ ) revealed that their potential for inhibition of cystatin $C$ dimerization seems to be similar. Whereas after 9 days of incubation in the presence of guanidinium chloride almost entire cystatin $C$ was found to be in the dimeric form, the addition of any of the hCC antibody (molar ratio 1:10) slowed down 3D domain swapping process and preserved about $60 \%$ of hCC in the monomeric form (Figure 8).

\section{DISCUSSION}

The stability of the antigen-antibody complex and molecular recognition is driven by non-covalent interactions. Complexes of this type are characterized by very low complementarity, and are mostly stabilized by hydrophobic and electrostatic interactions and hydrogen bonding. Knowledge of the amino acid sequence of the epitope provides the opportunity to regulate humoral immune responses in our immune system and encourage scientist to find new applications for antibodies like a design of new inhibitors for pathological processes. In this study, we investigated the binding epitope of hCC responsible for
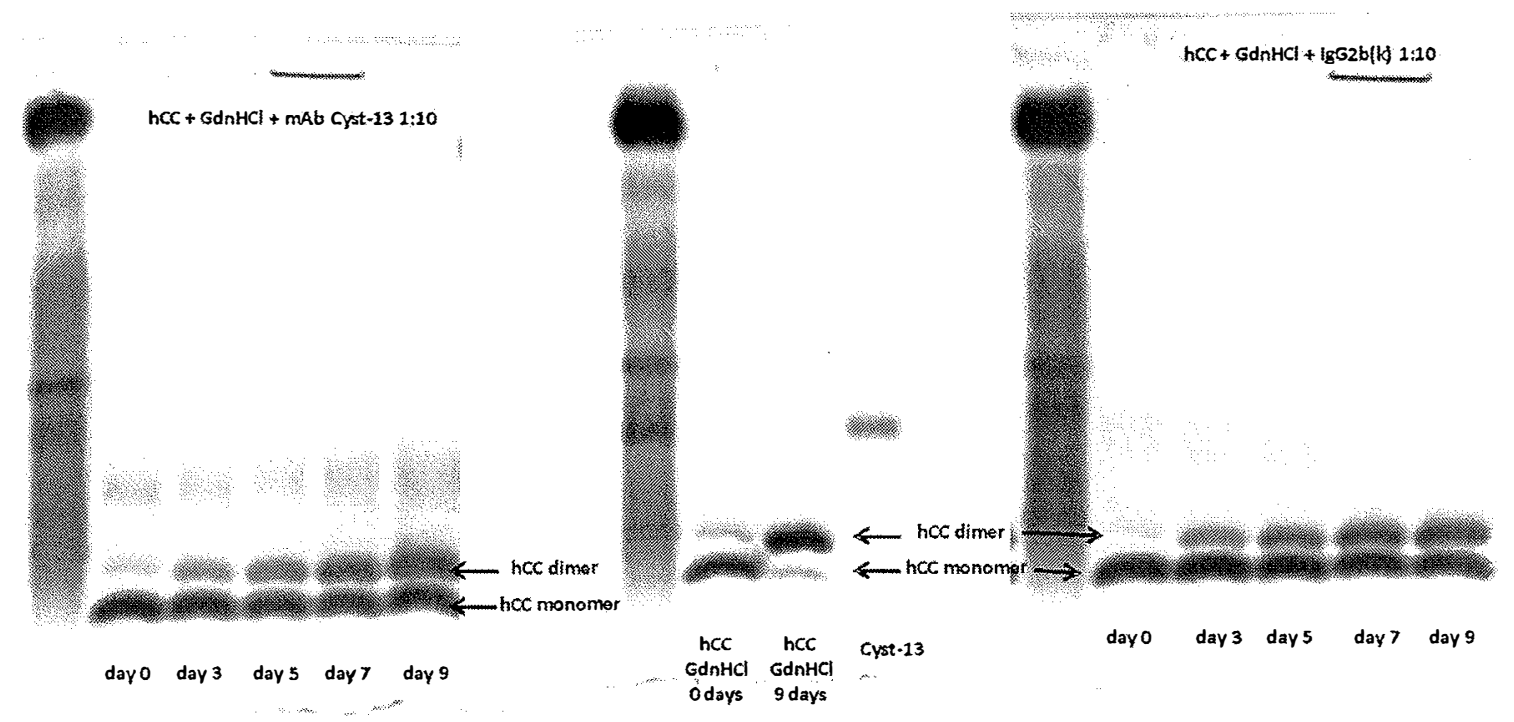

Figure 8. Gel electrophoresis comparison for 1:10 mAb: hCC incubated for 9 days. 


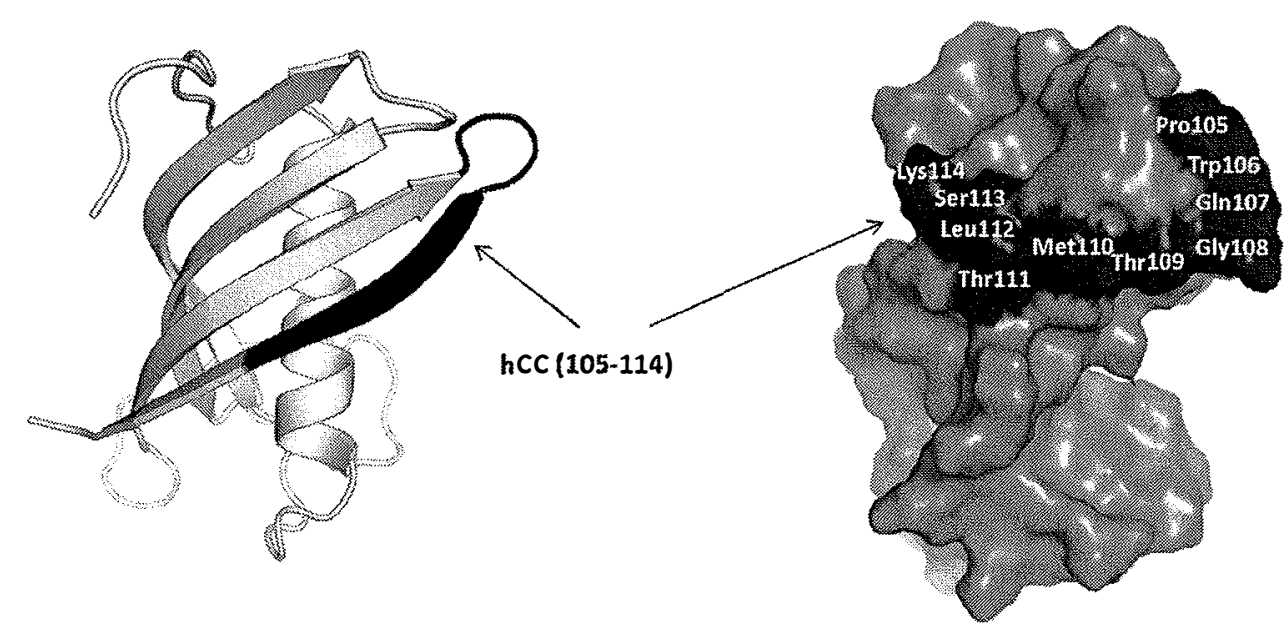

Figure 9. Primary sequence and structure model of cystatin C (ribbon diagram), and accessible surface area of pronase fragment hCC (105-114) identified by mass spectrometry. Structure model were prepared with PyMol program based on monomeric structure constructed using X-ray crystal of dimeric wt hCC as described by Rodziewicz-Motowidło et al., 2006.

recognition by monoclonal antibody Cyst-13. The studies were carried out using a molecular affinity mass spectrometry approach. The method makes use of the resistance of the epitope sequence to enzymatic digestion due to the shielding of the protein-antibody interaction structure. Analysis of the MS spectra obtained in the proteolytic excision/extraction procedure led us to the epitope identification and location. The results of digestions with the use of different enzymes and the analysis of the MS spectra obtained at successive steps of the extraction/ excision procedures revealed that the epitope for mAb Cyst-13 comprises residues 107-114 of hCC (QGTMTLSK). Literature data suggest that an epitope is generally composed of five to seven core amino acids and up to 10 contact residues. Our results correspond to these data very well, as we identified eight amino acid residues as the direct epitope. The binding experiment with the synthetic octapeptide showed however, that this sequence may be too short to ensure sufficient binding to the antibody and additional amino acid residues may be necessary to create a stable complex. Indeed, prolongation of the epitope from the $\mathrm{N}$ terminus by two residues resulted in the decapeptide PWQGTMTLSK showing much higher binding ability in the binding experiment. It was proved that prolongation of the epitope sequence by two residues stabilizes the complex and ensures the specificity of the molecular recognition. The determined epitope sequence is located in C-terminal region of cystatin $C$ which is exposed to the environment and where there is no steric hindrance which can impede interactions between hCC and the antibody (Figure 9). The presence of the epitope on the hCC surface guarantees the accessibility of the antigen determinant to the antibody. The epitope sequence (hCC $107-114$ ) is located within L2- $\beta 5$ strand. More importantly, this part is not directly engaged in the dimer formation as it occurs by the 3D domain swapping of the $\alpha$-helix and its two flanking $\beta$ - strands (Jaskolski 2001; Janowski et al., 2001, 2005). The location of the epitope suggests that the hCC dimer should also be able to interact with mAb Cyst-13. Previously, using the same methodology, we identified the binding sites for hCC-A $\beta$ complex (Juszczyk et al., 2009). It is interesting that the hCC binding site of amyloid beta-hCC (101-117)-A $\beta(17-24)$, comprises the epitopic sequence found for mAb Cyst-13, hCC (107-114).

The epitope peptide shows some tendency to form bent or helical structure. This feature, weakly visible in the CD spectra was clearly observed in the NMR experiments (Figure 6). Interestingly, no addition of TFE was needed to detect helix formation in the octapeptide (NMR spectra were recorded in water). In all families of conformations obtained after cluster analysis the bent or helical fragment were clearly seen. The slight difference between the octapeptide structure deduced from CD and NMR spectroscopy arises probably from the fact that in general, CD spectroscopy shows the averaged secondary structure of peptides and proteins based on the backbone properties in relation to circularly polarized light absorption. Because linear peptides are generally very flexible, most often their structure observed by CD spectroscopy without any inducer (e.g., TFE) is very random (Skwierawska et al., 2008). On the other hand, NMR spectroscopy, which gives insight into the atomic nature of molecules, is able to register even the weakest signs of a regular structure formation. Because of the fast hydrogen/deuterium exchange and conformational dynamics of the 10-amino-acidresidue fragment, we were not able to record fully interpretable 2D 'H-NMR spectra for the decapeptide. However, CD spectroscopy gives us some indications that this peptide has some propensity to form a helical conformation, which is more pronounced even in lower TFE concentration compared to that of octapeptide (Figure 4). Based on the results obtained so far, both from CD and NMR spectroscopy, it is indubitable that the epitope 
peptide appears to adopt a helical-type conformation in solution. Interestingly, the same sequence, when analyzed in the whole hCC molecule, exists in an $\mathrm{N}$-terminally-bent/extended conformation as a part of a $L 2$ turn and $\beta 5$ strand, thus bearing little similarity to the structure detected for the synthetic peptide. This discrepancy is understandable as the conformation and structural properties of a peptide of a given sequence is strongly dependent on the peptide length, environmental factors and the type and strength of stabilizing forces (hydrogen bonds, hydrophobic interactions) which are different for an isolated peptide in solution and when it is a part of a bigger molecule. Nevertheless, structural studies like the ones performed for our epitope peptide provide information concerning its structure in solution, which may differ from the one observed for the peptide engaged in the interaction with antibody. Such information may be useful in a design of molecules based on the target epitope sequence that can serve as e.g., potential inhibitors of dimerization or oligomerization process of hCC, since it shows that the recognition does not have to be strictly based on the particular structure and some conformational freedom is often available. To decide whether the helical-type conformation of the epitope peptide is necessary for its recognition and antibody binding, more structural studies are necessary. The identification of the binding site may be of high importance for dimerization/ oligomerization and fibrillization studies of hCC. Gel electrophoresis proved the direct influence of mAb Cyst-13 on the dimerization of hCC. It is then very interesting how blocking of the C-terminal part by interaction with the antibody can influence the dimerization process. The question needs further investigation.

The knowledge of the epitope sequence may be extremely useful in future in vitro studies of hCC fibril formation, since the pathogenic $L 68 \mathrm{Q}$ mutant responsible for HCCAA easily forms fibrils probably according to the same mechanism as wt cystatin $\mathrm{C}$ dimers are formed. In the model of hCC fibrils postulated by
Jaskolski, the assigned epitope sequence located close to the center of fibrils would provide the opportunity to disturb the interaction between cystatin $\mathrm{C}$ molecules by binding of $\mathrm{mAb}$ to the C-terminal part of monomeric hCC (Jaskolski, 2001). The identified epitope could also be used as a new template for designing efficient inhibitors for the dimerization/oligomerization process. The identification of the paratope is in progress and we hope that it will soon be assigned.

\section{CONCLUSION}

Specific antibodies may serve as an important regulatory mechanism for different processes. Thanks to the use of the epitope extraction- and excision-mass spectrometry method, we were able to identify successfully the epitope for monoclonal antibody Cyst-13 raised against hCC. The epitope identification gives a possibility to use more defined active immunization with partial sequence of hCC conjugated to a carrier protein. This approach may yield a strong antibody response to a definite region of cystatin $C$. This epitope-based approach may be promising for combating pathological conditions related to hCC amyloidogenity (HCCAA).

\section{Acknowledgements}

We would like to thank Professor Anders Grubb from the University of Lund (University Hospital, Department of Clinical Chemistry, Institute of Laboratory Medicine, Sweden), for his great hospitality, for plasmid pHD313 and access to his laboratory equipment. We also thank Professor Stanisław Ołdziej for help with NMR experiments. This work is supported by the Polish Ministry of Science and Higher Education grant 1264/B/H03/ 2009/37 and DS/8440-4-0172-0.

\section{REFERENCES}

Abrahamson M, Grubb A. 1994. Increased body temperature accelerates aggregation of the Leu68GIn mutant cystatin C, the amyloid-forming protein in hereditary cystatin $\mathrm{C}$ amyloid angiopathy. Proc. Natl. Acad. Sci. U.S.A. 91(4): 1416-1420.

Antonyuk SV, Trevitt CR, Strange RW, Jackson GS, Sangar D, Batchelor M, Cooper S, Fraser C, Jones S, Georgiou T, Khalili-Shirazi A, Clarke AR Hasnain SS, Collinge J. 2009. Crystal structure of human prion protein bound to a therapeutic antibody. Proc. Natl. Acad. Sci. U.S.A. 106: 2554-2558.

Atherton E, Sheppard RC. 1989. Solid Phase Peptide Synthesis, Rickwood D, Hames BD (eds). IRL Press: Oxford, UK.

Bard F, Cannon C, Barbour R, Burke RL, Games D, Grajeda H, Guido T, Hu K Huang J, Johnson-Wood K, Khan K, Kholodenko D, Lee M, Lieberburg I, Motter R, Nguyen M, Soriano F, Vasquez N, Weiss K, Welch B, Seubert $P$, Schenk D, Yednock T. 2000. Peripherally administered antibodies against amyloid beta-peptide enter the central nervous system and reduce pathology in a mouse model of Alzheimer disease. Nat. Med. 6: 916-919.

Bartels C, Xia TH, Billeter M, Güntert P, Wüthrich K. 1995. The program XEASY for computer-supported NMR spectral-analysis of biological macromolecules. J. Biomol. NMR 6: 1-10.

Bax A, Davis DG. 1985. Practical aspects of two-dimensional transverse NOE spectroscopy. J. Magn. Reson. 63: 207-213.

Bax A, Freeman R. 1985. Enhanced NMR resolution by restricting the effective sample volume. J. Magn. Reson. 65: 355-360.
Bystrov VF. 1976. Spin-spin coupling and the conformational states of peptide systems. Progr. NMR Spectrosc. 10: 41-81.

Calero M, Pawlik M, Soto C, Castano EM, Sigurdsson EM, Kumar A, Gallo G, Frangione $B$, Levy E. 2001. Distinct properties of wild-type and the amyloidogenic human cystatin $C$ variant of hereditary cerebral hemorrhage with amyloidosis, icelandic type. J. Neurochem. 77(2): 628-637. DOI: 10.1046/j. 1471-4159. 2001.00256x

Case DA, Cheatham TE III, Simmerling CL, Wang J, Duke RE, Luo R, Merz KM, Pearlman DA, Crowley M, Darden T, Brozell S, Tsui V, Gohlke H, Mongan J, Beroza P, Schafmeister C, Caldwel JW, Ross WS, Kolman PA $\mathrm{n}$ J, Hornak V. 2004. AMBER8, University of California, San Francisco.

Coin I, Beyermann M, Bienert M. 2007. Solid-phase peptide synthesis: from standard procedures to the synthesis of difficult sequences. Nat. Protoc. 2(12): 3247-3256. DOI: 10.1038/nprot:2007.454

Colby DW, Chu Y, Cassady JP, Duennwald M, Zazulak H, Webster JM, Messer A, Lindquist S, Ingram VM, Wittrup KD. 2004. Potent inhibition of huntingtin aggregation and cytotoxicity by a disulfide bond-free single-domain intracellular antibody. Proc. Natl. Acad. Sci. U.S.A. 101: 17616-17621.

Darden T, York D, Pedersen L. 1993. Particle Mesh Ewald-an n.log(n) method for Ewald sums in large systems. J. Chem. Phys. 98: 1008910092.

Donofrio G, Heppner FL, Polymenidou M, Musahl C, Aguzzi A. 2005 Paracrine inhibition of prion propagation by anti-PrP single-chain Fv miniantibodies. J. Virol. 79: 8330-8338. 
Ekiel I, Abrahamson M. 1996. Folding-related dimerization of human cystatin C. J. Biol. Chem. 271: 1314-1321.

Ewald PP. 1921. The calculation of optical and electrostatic grid potential. Ann. Phys. 64: 253-287.

Fields GB, Noble RL. 1990. Solid-phase peptide synthesis utilizing 9fluorenylmethoxycarbonyl amino acids. Int. J. Pept. Protein Res. 35: 161-214.

Gottlieb HE, Kotlyar V, Nudelman A. 1997. NMR chemical shifts of common laboratory solvents as trace impurities. J. Org. Chem. 62(21): 75127515.

Grubb AO. 2000. Cystatin C-properties and use as diagnostic marker. Adv. Clin. Chem. 35: 63-99.

Guntert P, Braun W, Wüthrich K. 1991. Efficient computation of threedimensional protein structures in solution from nuclear magnetic resonance data using the program DIANA and the supporting programs CALIBA, HABAS and GLOMSA. J. Mol. Biol. 217(3): 517530. DOI: 10.1016/0022-2836(91)90754-T

Guntert P, Mumenthaler C, Wüthrich K. 1997. Torsion angle dynamics for NMR structure calculation with the new program DYANA. J. Mol. Biol. 273(1): 283-298. DOl: 10.1006/jmbi. 1997. 1284

Guntert P, Wüthrich K. 1991. Improved efficiency of protein structure calculations from NMR data using the program DIANA with redundant dihedral angle constraints. J. Biomol. NMR 1(4): 447-456.

Hochleither EO, Gorny MK, Zolla-Pazner S, Tomer KB. 2000. Mass sectrometric characterization of a discontinous epitope of the HIV envelope protein HIV-gp 120 recognized by the human monoclonal antibodies 1331A. J. Immunol. 164(8): 4156-4161.

Janowski R, Kozak M, Abrahamson M, Grubb A, Jaskolski M. 2005. 3D domain-swapped human cystatin $C$ with amyloid-like intermolecular beta-sheets. Proteins 61(3): 570-578. DOI: 10.1002/prot.20633

Janowski R, Kozak M, Jankowska E, Grzonka Z, Grubb A, Abrahamson M, Jaskolski M. 2001. Human cystatin C, an amyloidogenic protein, dimerizes through three-dimensional domain swapping. Nat. Struct. Biol. 8(4): 316-320. DOI: $10.1038 / 86188$

Jaskolski M. 2001. 3D domain swapping, protein oligomerization, and amyloid formation. Acta Biochim. Pol. 48(4): 807-827.

Jemmerson R, Paterson Y. 1986. Mapping epitopes on a protein antigen by the proteolysis of antigen-antibody complexes. Science 232(4753): 1001-1004. DOI: $10.1126 /$ science.2422757

Jeyarajah S, Parker CE, Summer MT, Tomer KB. 1998. Matrix-assisted laser desorbtion ionization/mass spectrometry mapping of human immunodeficiency virus-gp 120 epitopes recognized by a limited polyclonal antibody. J. Am. Soc. Mass Spectrom. 9(2): 157-165. DOI: 10.1016/ S1044-0305(97)00247-X

Juszczyk P, Paraschiv G, Szymanska A, Kolodziejczyk AS, RodziewiczMotowidlo S, Grzonka Z, Przybylski M. 2009. Binding epitopes and interaction structure of the neuroprotective protease inhibito cystatin $C$ with beta-amyloid revealed by proteolytic excision mass spectrometry and molecular docking simulation. J. Med.Chem. 52(8) 2420-2428. DOI: 10.1021/jm801115e

Koradi R, Billeter M, Wuthrich K. 1996. MOLMOL: a program for display and analysis of macromolecular structures. J. Mol. Graph. 14(1):51-55 29-32.

Mahoney MW, Jorgensen WL. 2000. A five-site model for liquid water and the reproduction of the density anomaly by rigid, non-polarizable potential functions. J. Chem. Phys. 112: 8910-8922.

Nilsson $M$, Wang $X$, Rodziewicz-Motowidlo $S$, Janowski $R$, Lindstrom $V$, Onnerfjord P, Westermark G, Grzonka Z, Jaskolski M, Grubb A. 2004. Prevention of domain swapping inhibits dimerization and amyloid fibril formation of cystatin C: use of engineered disulfide bridges, antibodies, and carboxymethylpapain to stabilize the monomeric form of cystatin C. J. Biol. Chem. 279(23): 24236-24245. DOI: 10.1074/ jbc.M402621200

Olafsson I, Grubb A. 2000. Hereditary cystatin C amyloid angiopathy. Amyloid 7(1): 70-79.
Olafsson I, Lofberg H, Abrahamson M, Grubb A. 1988. Production, characterization and use of monoclonal antibodies against the major extracellular human cysteine proteinase inhibitors cystatin $\mathrm{C}$ and kininogen. Scand. J. Clin. Lab. Invest. 48(6): 573-582.

Pearlman DA, Kollman PA. 1991. Are time-averaged restraints necessary for nuclear magnetic resonance refinement? A model study for DNA. J. Mol. Biol. 220(2): 457-479. DOI: 10.1016/00222836(91) $90024-Z$

Piantini U, Sorensen OW, Ernst RR. 1982. Multiple quantum filters for elucidating NMR coupling networks. J. Am. Chem. Soc. 104: 68006801.

Rock KL. 1996. A new foreign policy: MHC class I molecules monitor the outside world. Immunol. Today 17: 131.

Rodziewicz-Motowidło S, Whlbom M, Wang X, Langiewka J, Janowski R, Jaskólski M, Grubb A, Grzonka Z. 2006. Checking the conformation stability of cystatin $C$ and its $L 68 Q$ variant by molecular dynamic studies: why is the L68Q variant amyloidogenic? J.Struc. Biol. 154(1): 68-78.

Ryckaert JP, Ciccotti G, Berendsen HJC. 1977. Numerical-integration of cartesian equations of motion of a system with constraintsmolecular-dynamics of n-alkanes. J. Comput. Phys. 23: 327-341.

Skwierawska A, Rodziewicz-Motowidło S, Ołdziej S, Liwo A, Sheraga HA. 2008. Conformational studies of the $\alpha$-helical 28-43 fragment of the immunoglobulin binding protein G B3 domain from Streptococcus. Biopolymers 89: 1032-1044. DOI: 10.1002/bip.21056

Stefanescu R, lacob RE, Damoc EN, Marquardt A, Amstalden E, Manea M, Perdivara I, Maftei M, Paraschiv G, Przybylski M. 2007. Mass spectrometric approaches for elucidation of antigen-antibody recognition structures in molecular immunology. Eur. J. Mass. Spectrom. 13(1):6975.

Szymanska A, Radulska A, Czaplewska P, Grubb A, Grzonka Z, RodziewiczMotowidlo S. 2009. Governing the monomer-dimer ratio of human cystatin $\mathrm{C}$ by single amino acid substitution in the hinge region. Acta Biochim. Pol. 56(3): 455-463.

Tabira T. 2010. Immunization therapy for Alzheimer disease: a comprehensive review of active immunization strategies. Tohoku J. Exp. Med. 220: 95-106.

Tian X, Cecal R, McLaurin J, Manea M, Kierstead ME, Phinney AL, French JE, Lambermon $M H$, Darabie $A A$, Brown ME, Janus C, Chishti MA, Horne $P$, Westaway D, Fraser PE, Mount HT, Przybylski M, St George-Hyslop P. 2002. Therapeutically effective antibodies against amyloid-beta peptide target amyloid-beta residues 4-10 and inhibit cytotoxicity and fibrillogenesis. Nat. Med. 8: 1263-1269. DOI: 10.1038/ $\mathrm{nm} 790$

Tian X, Cecal R, McLaurin J, Manea M, Stefanescu R, Grau S, Harnasch M, Amir S, Ehrmann M, St George-Hyslop P, Kohlmann M, Przybylski M. 2005. Identification and structural characterization of carboxyterminal polipeptides of Alzheimer's amyloid precursor protein using high-resolution mass spectrometry. Eur. J. Mass Spectrom. 11: 547555.

Tian X, Maftei M, Kohlmann M, Allinquant B, Przybylski M. 2007 Differential epitope identification of antibodies against intracellular domains of alzheimer's amyloid precursor protein using high resolution affinity-mass spectrometry. Subcell. Biochem. 43: 339-354.

Torda AE, Scheek RM, van Gunsteren WF. 1989. Time-dependent distance restraints in molecular-dynamics simulations. Chem. Phys. Lett. 157: 189-194.

Weiner SJ, Kollman PA, Nguyen DT, Case DA. 1987. An all atom force-field for simulations of proteins and nucleic-acids. J. Comput. Chem. 7: 230-252.

Wuertzer CA, Sullivan MA, Qiu X, Federoff HJ. 2008. CNS delivery of vectored prion-specific single-chain antibodies delays disease onset. Mol. Ther. 16: 481-486.

Wiithrich K. 1986. NMR of Proteins and Nucleic Acids. John Wiley Press: New York. 